\title{
Entre tradição e inovação: um estudo sobre mudanças no ensino de gramática em livros didáticos brasileiros de Língua Portuguesa1
}

\author{
Alexsandro da Silva \& Artur Gomes de Morais \\ Universidade Federal de Pernambuco, Brasil
}

\begin{abstract}
Resumo
O objetivo deste artigo é investigar o tratamento dado ao ensino de gramática ou à análise linguística em três coleções brasileiras de livros didáticos de Língua Portuguesa aprovadas no Programa Nacional do Livro Didático 2007. Os resultados evidenciaram que duas das coleções analisadas usavam o termo gramática e todas elas tendiam a estabelecer objetivos de ensino relacionados ao domínio da gramática ou da língua em si mesmas. Em relação aos conteúdos, constatamos que os tópicos tradicionais da gramática escolar dividiam a cena com outros conteúdos. Ao analisar as atividades, constatamos, em duas das coleções, poucas atividades de análise quando se tratavam dos conteúdos tradicionais. No ensino das classes de palavras e da ortografia, encontramos duas inovações principais: o uso de textos e a tendência à não-apresentação de informações prontas. Já na exploração de características dos gêneros textuais, além de usar pseudotextos, as coleções adotavam, às vezes, uma abordagem transmissiva.
\end{abstract}

Palavras-chave

Análise linguística; Ensino de gramática; Livros didáticos

\section{Introdução}

Desde meados da década de 1980, os discursos sobre o ensino de língua materna no Brasil têm assumido o texto como unidade didática 
privilegiada e evidenciado a relevância da leitura e da produção de textos nas aulas de Língua Portuguesa. Esses mesmos discursos têm também denunciado a manutenção de um ensino de gramática centrado em nomenclaturas e classificações com fins em si mesmas, que, conforme observou Neves (2003), desconsidera a reflexão sobre o funcionamento da linguagem.

Como analisa Soares (1998), é nesse contexto, com a redemocratização do país e com a contribuição das disciplinas linguísticas (Sociolinguística, Psicolinguística, Linguística Textual, Pragmática e Análise do Discurso) ao ensino de língua portuguesa, que uma nova concepção de linguagem começou a orientar o ensino nessa área: "uma concepção que vê a língua como enunciação, discurso, [...] que, portanto, inclui as relações da língua com aqueles que a utilizam, com o contexto em que é utilizada, com as condições sociais e históricas de sua utilização" (Soares, 1998, p. 59).

Ao mesmo tempo, como dissemos, os discursos sobre a prática docente nessa área denunciavam a manutenção de um ensino transmissivo da gramática na escola, que se restringia à identificação e à classificação de formas linguísticas e ao estudo da "língua padrão", seguindo uma orientação dedutiva (conceito ou regra - exemplo - exercício). Essas críticas constituíram uma tentativa de questionar a importância da tradição gramatical, ainda tão arraigada no contexto escolar, uma vez que, como observava Batista (1997), quando se ensina Português na escola, ensina-se, basicamente, gramática.

Embora o ensino de gramática agora descrito apareça de maneira mais nítida a partir do $6^{\circ}$ ano do Ensino Fundamental brasileiro ${ }^{2}$, é incontestável que a tradição gramatical começa a se instalar nas escolas brasileiras já nos anos iniciais do Ensino Fundamental, sobretudo nos $4^{\circ}$ e $5^{\circ}$ anos, quando se observa um investimento significativo em aulas de gramática, com ênfase no estudo de nomenclaturas e classificações (Morais, 2002; Souza, 2010; Silva \& Silva, 2010).

Em contraposição a esse ensino tradicional da gramática escolar, passamos a defender a "prática de análise linguística" como uma das unidades básicas do ensino de português, conforme sugerido por Geraldi (1997[1984]). Segundo este autor, o uso dessa expressão "não se deve ao mero gosto por novas terminologias", pois a "análise linguística" incluiria 
"tanto o trabalho sobre questões tradicionais da gramática quanto questões mais amplas a propósito do texto" (p. 74).

A fim de contribuir com essa discussão, apresentaremos, neste artigo, resultados de um estudo que desenvolvemos com o objetivo de investigar como livros didáticos brasileiros da área de língua portuguesa dos anos iniciais do Ensino Fundamental estão tratando o eixo didático designado como "gramática" ou "análise linguística", analisando mudanças em relação ao ensino tradicional ${ }^{3}$ da gramática escolar.

Assumindo essa perspectiva, discutiremos, a seguir, algumas questões relativas à temática deste artigo. Em seguida, após caracterizarmos as coleções de livros didáticos analisadas e descrevermos a metodologia adotada em nossa investigação, discutiremos os principais resultados que encontramos, ao analisar tais coleções.

\section{Análise linguística na escola: novas perspectivas, novos desafios}

A partir da concepção de linguagem como forma de interação social, Geraldi (1997[1984]) propôs uma reorientação do ensino de Português, com base na integração das práticas de leitura, produção de textos e análise linguística. Para este autor, a prática de análise linguística seria caracterizada pela reescrita dos textos produzidos pelos alunos nas aulas de produção de textos, enfocando um aspecto selecionado como tema da aula de prática de análise linguística.

Essa nova expressão relaciona-se, tal como aponta Morais (2002), a uma complexa ampliação do eixo didático designado tradicionalmente de "gramática", que agora incluiria não apenas os conhecimentos relacionados à norma linguística de prestígio, mas também àqueles que dizem respeito ao texto e ao discurso.

Nessa nova perspectiva, sugere-se, então, que a reflexão sobre a língua não se atenha apenas ao nível da palavra e da frase, mas incida também sobre o texto e o discurso. Essa orientação vai ao encontro, portanto, de um ensino de gramática pautado nos usos da língua e a serviço deles. Para tanto, seria necessário tratar, na escola, a análise e reflexão sobre os fenômenos linguísticos de outra maneira, o que demandaria, como esclarece 
Neves (2003), uma gramática orientada pela observação dos usos linguísticos.

Apesar de termos vivido um amplo debate, nas duas últimas décadas, sobre o ensino da língua materna, ainda não parecem ter se efetivado grandes mudanças nas aulas de gramática, que tenderiam a continuar restritas à exporação de nomenclaturas e de classificações. No entanto, entendemos, a despeito disto, que os professores estão encontrando soluções alternativas para inovar o ensino de gramática, mesmo que estas não se coadunem às expectativas que nós, especialistas da área, temos.

Contribuindo para entendermos melhor este quadro de realidade, Morais (2002) desenvolveu uma pesquisa com 12 professoras de $3^{\mathrm{a}}$ e $4^{\mathrm{a}}$ séries da rede pública municipal de Recife (Pernambuco, Região Nordeste do Brasil). A partir da realização de entrevistas com estas docentes, constatou que os seus discursos revelavam evidentes tentativas de inovação, que se expressaram nas intenções de fazer um estudo "prazeroso" de aspectos normativos "atrelados ao texto" e no esforço de não-identificação com a transmissão de regras e categorias gramaticais desvinculadas dos textos.

Ao serem indagadas sobre os objetivos do ensino de língua portuguesa, a maior parte dos depoimentos das mestras participantes da pesquisa supracitada remetiam a uma preocupação em formar alunos que "lessem com compreensão e produzissem textos", demonstrando uma apropriação das prescrições atualmente hegemônicas nessa área. Apesar disso, os temas ou objetos tratados como conhecimentos linguísticos, nas aulas, tendiam a concentrar-se nos velhos conteúdos da gramática escolar tradicional, como uso de letras maiúsculas, encontros vocálicos, número de sílabas das palavras, tonicidade das palavras, tipos de frases e classes de palavras (substantivo, adjetivo, pronome e verbo).

Ao analisar como dois professores dos anos iniciais do Ensino Fundamental (um de $4^{\circ}$ e outro de $5^{\circ}$ ano) de escolas da cidade de Caruaru (Pernambuco, Região Nordeste do Brasil) concebiam e praticavam o "ensino de gramática" ou a "análise linguística", Silva e Silva (2010) constataram tentativas de inovação nas concepções e práticas daqueles docentes, embora eles tenham demonstrado dificuldade em implementar um ensino que, de fato, rompesse com a tradição da gramática escolar. A partir da realização de observações e entrevistas semi-estruturadas, os autores observaram que 
essas tentativas de inovação eram evidentes quando, por exemplo, ao buscar distanciar-se dos moldes tradicionais desse ensino, os professores investiam no que se tem chamado de "gramática contextualizada", usando o texto como pretexto para o ensino de gramática.

\section{Currículo, livro didático e novas perspectivas para o ensino de gramática/análise linguística no Brasil}

Nesse cenário de mudanças, diversas redes de ensino públicas começaram a incorporar as novas orientações em seus documentos curriculares, como um meio de contribuir para a melhoria do ensino de língua no Brasil. Marinho (1998), ao analisar currículos de Língua Portuguesa do Ensino Fundamental das décadas de 80/90 de dezenove estados brasileiros, constatou uma tentativa - ainda que com contradições e distorções - de aproximação daqueles documentos às novas concepções divulgadas nos discursos dos especialistas dessa área. Segundo a autora, na realidade, tais propostas constituíram mais um "conjunto de intenções" que, propriamente, uma concretização de uma proposta de ensino centrada em uma abordagem discursiva e pragmática da linguagem.

De acordo com Marinho (1998), as propostas curriculares por ela analisadas, ancoradas, em sua maioria, na concepção de linguagem como interação (mas nem sempre de modo exclusivo), criticavam o ensino tradicional de Português, sugerindo, de modo geral, um deslocamento da "gramática" para o "texto". No entanto, conforme a autora, a gramática ocupava lugares diferentes nos diversos currículos, não sendo esta posição exclusiva. Havia alguns documentos que, explicitamente, situavam a gramática como o eixo principal do ensino de língua e outros que mantinham esta posição, mas sem a assumir claramente. Havia, ainda, aqueles que tentavam superar a tradição gramatical, subordinando o estudo dos conhecimentos linguísticos às dificuldades encontradas pelos alunos na leitura e na escrita de textos.

Essas tentativas de mudança nos documentos curriculares expressaram-se, também, em uma mudança terminológica. Em muitos dos currículos analisados, a seção relativa à "gramática" passou a ser chamada de "conhecimentos linguísticos". Contudo, conforme constatou Marinho 
(1998), a retirada do termo "gramática" não implicava, necessariamente, uma relativização ou diminuição do status da gramática escolar tradicional. A autora verificou, entre os currículos analisados, a coexistência da concepção de linguagem como interação e listas de conteúdos da gramática escolar tradicional, tais como as classes de palavras (substantivo, adjetivo, artigo, numeral, pronome, verbo, etc.).

Constatou-se, ainda, naquele estudo, que enquanto alguns currículos insistiam em delimitar os conhecimentos linguísticos a serem ensinados na escola, como aqueles da gramática escolar tradicional, outros os subordinavam às dificuldades observadas nas produções textuais dos alunos. Neste caso, alguns conteúdos eram indicados, mas, na maioria das vezes, eram deixados "em aberto". Essas duas posturas, de acordo com Marinho (1998), acabariam conduzindo à ênfase no estudo gramatical tradicional, quer pela insistência nele, quer pela omissão, o que deixaria uma lacuna a ser preenchida com o que se conhece (neste caso, os antigos conteúdos gramaticais).

Tal como os currículos, os livros didáticos brasileiros também mudaram nas últimas décadas. Criado em 1985 pelo Ministério da Educação (MEC) por meio do Decreto-Lei no 9.154, o Programa Nacional do Livro Didático (PNLD) teve suas características alteradas a partir de 1996, conforme destacam Batista \& Costa Val (2004). Segundo ainda esses autores, os objetivos centrais desse programa são, atualmente, a avaliação, aquisição e distribuição universal e gratuita de livros didáticos para os alunos das escolas públicas do ensino fundamental. Avaliados a cada três anos, os livros didáticos aprovados são incluídos no Guia de Livros Didáticos, que auxilia os professores na escolha dos livros que serão usados em sala de aula.

Como decorrência desse processo, temos assistido, nos últimos anos, a um processo de melhoria significativa dos livros didáticos que têm sido submetidos ao PNLD. Segundo Costa Val e Castanheira (2005), entre 1998 e 2004 observa-se uma diminuição do número de obras não aceitas e um aumento gradativo de obras aprovadas, na área de Alfabetização e Língua Portuguesa ( $1^{\text {a }}$ a $4^{\text {a }}$ séries). Essas autoras constataram, também, nesse mesmo período, um crescimento do volume de livros com menções mais altas (recomendados e recomendados com distinção), embora, em todas as avaliações, estas menções tenham sido menos frequentes que a mais baixa (recomendado com ressalvas) $^{4}$. 
Ao analisarem os resultados da avaliação dos livros didáticos de língua portuguesa ( $1^{\mathrm{a}}$ a $4^{\mathrm{a}}$ séries) do PNLD 2004, no que concerne ao trabalho voltado para os conhecimentos linguísticos, as autoras supracitadas constataram, no entanto, uma tendência de permanência da tradição gramatical, com altos índices relativos a conhecimentos morfológicos, semânticos (sinonímia, antonímia, paronímia e homonímia), morfossintaxe, fonologia e ortografia, e uma baixa frequência de atividades voltadas ao texto e ao discurso. As autoras também constataram um baixo percentual de obras que contemplavam o fenômeno social da variação linguística.

Biruel (2002), analisando duas coleções de livros didáticos de $1^{\mathrm{a}}$ a $4^{\mathrm{a}}$ séries ("ALP" e "Linguagem e Interação") recomendadas pelo PNLD 20002001, concluiu que o tratamento dado pelos autores aos aspectos normativos da língua pouco estimulou os alunos a observar, analisar e explicitar conhecimentos relativos à normatividade. Constatou-se, nesse estudo, que as coleções ainda revelavam uma concepção homogênea de língua e de norma culta, colaborando muito pouco para a superação da vinculação entre norma culta e gramática tradicional.

Visando a contribuir com essa discussão, desenvolvemos um estudo que teve como objetivo investigar o tratamento dado ao ensino de gramática ou à análise linguística em livros didáticos brasileiros da área de língua portuguesa dos anos iniciais do Ensino Fundamental, conforme dissemos anteriormente. Na seção a seguir, caracterizaremos as coleções analisadas e descreveremos os procedimentos metodológicos adotados.

\section{Coleções de livros didáticos analisadas e procedimentos metodológicos}

Neste estudo, usamos como estratégia metodológica a análise documental de três coleções de livros didáticos de língua portuguesa $\left(1^{\mathrm{a}}\right.$ a $4^{\mathrm{a}}$ séries), aprovadas no PNLD 2007, entendendo como documento toda fonte de informação já existente, que inclui não apenas documentos impressos, mas também documentos sonoros e visuais (Laville \& Dionne, 1999). Estas coleções foram escolhidas por terem sido as mais solicitadas pelas escolas públicas de Pernambuco, conforme dados constantes no site do Fundo Nacional para o Desenvolvimento da Educação (FNDE) ${ }^{5}$. Elas eram: 
- Coleção "Porta Aberta" (doravante PA), de Isabella Pessoa de Melo Carpaneda e Angiolina Domanico Bragança, FTD, 2005;

- Coleção "Projeto Pitanguá" (doravante PP), obra coletiva concebida, desenvolvida e produzida pela Editora Moderna, Moderna, 2005;

- Coleção "Os caminhos da Língua Portuguesa" (doravante CLP), de Maria do Rosário Gregolin, Editora Atual, 2004.

As três coleções foram examinadas a partir da análise de conteúdo: os dados "brutos" obtidos a partir da análise dos livros didáticos foram submetidos a análises de conteúdo, passando por processos de descrição, inferência e interpretação (Bardin, 1979). A análise de conteúdo foi desenvolvida por temas (análise temática categorial) e envolveu as etapas sugeridas por Bardin (1979), embora não necessariamente nessa ordem: préanálise, análise do material (codificação e categorização da informação) e tratamento dos resultados, inferência e interpretação.

Nesse processo, construímos as seguintes categorias analíticas: denominação dada ao eixo didático relativo à análise e reflexão sobre a língua; objetivos do ensino de "gramática" ou "análise linguística"; conteúdos do ensino de "gramática" ou "análise linguística"; tratamento didático da "gramática" ou "análise linguística".

\section{Que denominação era dada ao eixo de ensino relativo à gramática/análise linguística?}

A partir de um levantamento das denominações utilizadas pelas coleções aprovadas no PNLD 2007 para a seção tradicionalmente designada de "gramática", realizado a partir das resenhas que aparecem no Guia do Livro Didático de 2007, constatamos que a maioria das coleções aprovadas no PNLD 2007 - 24 de um total de 37 (em torno de 64\%) - não usou a palavra "gramática" para se referir ao eixo de ensino assim chamado na tradição escolar. Quando procediam desta maneira, grande parte das coleções -18 de um total de 37 (em torno de $48 \%$ ) - empregava as palavras "língua" e "linguagem", o que parece atestar uma adesão, no plano terminológico, a um conceito mais amplo de "análise linguística": não se trata de estudar a gramática, mas, sim, a língua, que, como esclarece Antunes (2007), inclui não 
apenas aquela, mas também o léxico e supõe regras de textualização e normas sociais de atuação.

Observamos, ainda, que as coleções que usavam os termos "língua" e "linguagem" tendiam a usar também expressões que remetiam, de certo modo, a uma representação de aluno como sujeito da aprendizagem, como ocorre em "Pensando sobre a língua", "Refletindo sobre a linguagem", "Trabalhando a linguagem" e "Descobertas sobre a língua", o que parece revelar uma apropriação, nas escolhas lexicais, de teorias construtivistas da aprendizagem. Entre as coleções que não empregavam o termo "gramática", verificamos que duas delas recorriam à palavra "texto" no título da seção ("A construção do texto na fala e na escrita" e "Estudando o texto"), o que talvez se relacione a uma maior influência dos estudos da Linguística Textual.

Em suma, as coleções aprovadas no PNLD 2007 tenderam a não utilizar o termo "gramática". Quando o usavam, recorriam, eventualmente, a expressões que atribuíam um sentido ativo à sua aprendizagem, ou então a relativizavam. Acreditamos que isso reflete uma tentativa de distanciamento de certa tradição de ensino comumente associada à palavra "gramática", uma tradição que deveria ser abandonada, dando lugar ao "novo".

Quando analisamos o tratamento dado ao ensino de "gramática" ou à "análise linguística" nas coleções de livros didáticos, constatamos que uma delas (PP) usou a nomenclatura "Estudo da língua" para o eixo didático designado na tradição escolar como "gramática", enquanto que as outras duas empregaram as denominações "Gramática" (PA) e "Descobrindo a gramática" (CLP) 6 . Constatamos, assim, que apenas uma das coleções analisadas (PP) deixou de usar a denominação "gramática", o que talvez reflita uma tentativa de distanciamento da tradição gramatical.

Na realidade, essa mudança terminológica não garante, por si só, uma mudança de concepção sobre o ensino de gramática, que poderia continuar apegado à velha transmissão de nomenclaturas e classificações, apesar da mudança de denominação. Por outro lado, essa "troca de nomes" não constitui nem mesmo consenso entre os estudiosos da área, que, muitas vezes, tendem a manter a designação ensino de "gramática", apesar de analisarem os fenômenos gramaticais a partir de uma perspectiva textual e discursiva. 


\section{Quais eram os objetivos do ensino de gramática/análise linguística?}

Com relação aos objetivos do ensino de "gramática" ou "análise linguística", constatamos que as coleções PA e CLP estabeleciam, no manual do professor, metas mais relacionadas ao domínio da gramática em si mesma, sem mencionar explicitamente o desenvolvimento das capacidades de leitura/escuta e de produção de textos orais e escritos. Já a coleção PP se remeteu não apenas ao conhecimento da língua e do seu funcionamento, mas também ao uso dela, o que estaria relacionado ao desenvolvimento da competência linguística dos alunos.

No manual do professor da coleção PA, considerava-se que o ensino de gramática teria como objetivo levar o aluno a "refletir sobre as modalidades oral e escrita da língua e mostrar-Ihe como se organizam e se articulam para produzir novos e diferentes significados" (p. 9). Já no manual da coleção PP, esclarecia-se que os conteúdos desenvolvidos na seção relativa aos conhecimentos linguísticos permitiriam ao aluno "conhecer o funcionamento da língua e utilizá-la de acordo com suas finalidades comunicativas" (p. 15). Segundo o manual da coleção CLP, o objetivo do ensino de gramática seria o de levar o aluno a "entender a estrutura e as noções gramaticais e, através da construção de hipóteses sobre o sistema da língua, compreender o funcionamento da linguagem" (p. 15).

Embora não tenham assumido claramente que o objetivo do ensino de gramática ou da análise linguística seria o de melhorar as capacidades de compreensão e produção de textos orais e escritos dos alunos, constatamos que as coleções analisadas apresentaram indícios de que estariam levando em consideração a existência de relações entre aqueles eixos didáticos, sendo a análise e reflexão sobre a língua um instrumento para a leitura e a produção de textos, tal como pode ser constatado no seguinte trecho do manual do professor da $1^{a}$ série da coleção PP: "Mantendo estreitas relações com a leitura e a produção de textos, também o domínio da língua, em suas diversas situações de uso, é condição básica para uma efetiva participação social" (p. 5).

Ainda nessa perspectiva, observamos que as coleções analisadas apresentavam seções específicas para o tratamento da "gramática" ou 
"análise linguística" e, apesar disso, traziam também atividades que poderiam ser consideradas como relativas a esse eixo didático em outras seções, como as de leitura e produção de textos. Provavelmente, isso reflete uma tentativa de apropriação de um discurso a favor da articulação entre os eixos do "uso" e da "reflexão" sobre a língua.

Essa proposta representa, portanto, uma mudança em relação ao antigo ensino de conhecimentos gramaticais, se considerarmos que as aulas de gramática não se relacionavam, via de regra, com as de leitura e de produção textual.

Se estivermos de acordo quanto à necessidade e à adequação de articularmos as situações de compreensão e produção de textos às de análise e reflexão sobre a língua, sobretudo nas séries/anos iniciais da escolarização, devemos, então, esclarecer que esta proposta não pode ser confundida, em hipótese alguma, com aquela em que se estuda gramática à parte, para, posteriormente, aplicá-la na leitura e na produção de textos.

\section{Que conteúdos de gramática/análise linguística eram explorados?}

Constatamos que, nos livros didáticos, os "tradicionais" conteúdos de gramática (como "ortografia" e "classes de palavras") dividiam a cena com outros conteúdos de "análise linguística" (como "características dos diversos gêneros de texto"), embora aqueles ainda ocupassem um espaço bastante significativo nas obras, tal como podemos observar na Tabela 1. Essa combinação atenderia, assim, ao mesmo tempo, à necessidade de mudança e à de manutenção do ensino da tradicional gramática escolar, conforme também observou Aparício (2006), ao analisar livros didáticos de língua portuguesa dos anos finais do Ensino Fundamental. 
Tabela 1 - Distribuição das atividades de "análise lingüística", por conteúdo, nas coleções de livros didáticos analisadas

\begin{tabular}{|c|c|c|c|c|c|c|}
\hline \multirow[t]{2}{*}{ Conteúdos } & \multicolumn{2}{|c|}{ Porta Aberta } & \multicolumn{2}{|c|}{ Projeto Pitanguá } & \multicolumn{2}{|c|}{$\begin{array}{l}\text { Os caminhos da } \\
\text { Língua } \\
\text { Portuguesa }\end{array}$} \\
\hline & n. & $\%$ & n. & $\%$ & n. & $\%$ \\
\hline $\begin{array}{l}\text { 1. Caracteristicas de gêneros, } \\
\text { tipos ou suportes de texto }\end{array}$ & 156 & 14,6 & 173 & 18,3 & 53 & 10,3 \\
\hline $\begin{array}{l}\text { 2. Efeitos de sentido decorrentes } \\
\text { do uso de recursos Ingüisticos } \\
\text { e/ou gráfico-visuais }\end{array}$ & 42 & 3,9 & 32 & 3,4 & 15 & 2,9 \\
\hline 3. Coesão textual & 44 & 4,1 & 34 & 3,6 & 27 & 5,3 \\
\hline 4. Pontuação/Paragrafaçāo & 114 & 10,7 & 47 & 5,0 & so & 9,7 \\
\hline 5. Ortografia & 289 & 27,1 & 254 & 26,9 & 169 & 32,9 \\
\hline 6. Variaçăo Ingüistica & 46 & 4,3 & 41 & 4,3 & 23 & 4,5 \\
\hline 7. Letras maiúsculas & 16 & 1,5 & 21 & 2,2 & 5 & 1,0 \\
\hline 8. Revisão de texto & 46 & 4,3 & 68 & 7,2 & 1 & 0,2 \\
\hline 9. Classes de palavras & 232 & 21,8 & 154 & 16,3 & 133 & 25,9 \\
\hline 10. Frase, oração e periodo & 5 & 0,5 & 7 & 0,7 & 0 & 0,0 \\
\hline 11. Formação de palavras & 8 & 0,8 & 40 & 4,2 & 7 & 1,4 \\
\hline 12. Uso do dicionánio & 5 & 1,9 & 25 & 2,6 & 2 & 0,4 \\
\hline 13. Ordem alfabética & 20 & 3,4 & 18 & 1,9 & 20 & 3,9 \\
\hline 14. Outros & 43 & 4.0 & 31 & 3,2 & 8 & 1,5 \\
\hline Total & 1.066 & 100,0 & 945 & 100,0 & 513 & 100,0 \\
\hline
\end{tabular}

Observamos, conforme os dados da Tabela 1, que diversos conteúdos de "análise linguística" apareceram nas coleções analisadas, desde os mais tradicionais no ensino da gramática escolar (como classes de palavras, ortografia e pontuação), até outros normalmente não contemplados naquele ensino (características de diferentes gêneros textuais, efeitos de sentido visados pelo autor do texto, variação linguística, etc.).

Esse dado parece confirmar, assim, a ocorrência, nos novos livros didáticos, de uma ampliação do eixo de ensino relativo à reflexão sobre a língua, que, na tradição escolar, incluía, quase que exclusivamente, conhecimentos ortográficos, morfológicos e sintáticos. Essa ampliação aproximaria eixos didáticos tratados isoladamente durante muito tempo gramática, de um lado, compreensão e produção de textos, do outro - e, ao mesmo tempo, tornaria os limites entre eles nem sempre tão simples de estabelecer. 
Observando, mais uma vez, os dados da Tabela 1, constatamos que, de um modo geral, os conteúdos que mais apareceram nas três coleções foram "ortografia" (PA - 27,1\%; PP - 26,9\%; CLP - 32,9\%), "classes de palavras" (PA - 21,8\%; PP - 16,3\%; CLP - 25,9\%) e "características de gêneros, tipos ou suportes de texto"7 (PA - 14,6\%; PP - 18,3\%; CLP $10,3 \%$ ). Esses dados sugerem, à primeira vista, uma mudança em termos dos conteúdos privilegiados no eixo relativo à reflexão sobre a língua, uma vez que conhecimentos textuais e discursivos, ainda que em uma proporção menor, dividem a cena com os consolidados na tradição do ensino da gramática escolar (ortografia e classes de palavras).

Em todas as coleções por nós analisadas, a "ortografia" - tópico presente em 88\% das obras aprovadas pelo PNLD 2007, segundo o Guia de Livros Didáticos (Brasil, 2006) - constituiu o conteúdo predominante (PA 27,1\%; PP - 26,9\%; CLP - 32,9\%), o que pode ser explicado pelo fato de haver, em todas as coleções, uma seção especificamente voltada ao estudo da norma ortográfica: PA - "Com que letra?"; PP - "Ortografia"; CLP "Atividades de ortografia".

Nas coleções PA e CLP, depois de "ortografia", apareceram, como conteúdos mais frequentes, "classes de palavras" (232 e 133 atividades, respectivamente) e "características de gêneros, tipos ou suportes de texto" (156 e 53 atividades, respectivamente). Já na coleção PP, encontramos mais atividades relativas às "características de gêneros, tipos ou suportes de texto" (173) que aquelas voltadas ao estudo das "classes de palavras" (154). Observamos, ainda, que a coleção CLP foi a que menos investiu no tratamento das "características de gêneros, tipos ou suportes de texto" (53 atividades contra 156 e 173 nas duas outras coleções).

Esses resultados revelam, assim, uma provável maior influência nas outras duas coleções das perspectivas mais recentes sobre o ensino de "análise linguística", a partir de gêneros textuais, que não consiste em retirar palavras de um texto e analisá-las morfológica ou sintaticamente, mas, sim, refletir sobre aspectos como o conteúdo temático (o que é dizível por meio do gênero), a construção composicional (a forma de organização do que se diz) e o estilo (meios linguísticos que são usados para dizer o que se quer dizer) característico de um gênero, isto é, aquilo que ele tem de especial (Schneuwly \& Dolz, 2004; Mendonça, 2006b). 
Por outro lado, constatamos, nas três coleções, um investimento significativo no estudo das "classes de palavras", conteúdo com alta incidência no ensino da gramática escolar, conforme apontaram estudos desenvolvidos com professores do ensino fundamental e médio (cf. Neves, 1990; Morais, 2002). Nesse sentido, as coleções por nós analisadas parecem não se enquadrar na tendência geral observada nas obras aprovadas no PNLD 2007, pois a maior parte das coleções "trata da gramática aplicada ao texto, [...] preferindo enfocar aqueles funcionamentos essenciais da língua escrita para produção de textos (concordância, coesão, discurso direto e indireto, pontuação, paragrafação, etc.)" (Brasil, 2006, p. 18).

Considerando, agora, a distribuição dos conteúdos de "análise linguística" nas seções didáticas de cada uma das obras, constatamos, nas três coleções, que, de fato, a maior parte das atividades relativas àquele eixo didático encontravam-se nas seções destinadas explicitamente ao estudo dos conhecimentos lingüísticos.

$\mathrm{Na}$ coleção $\mathrm{PA}$, percebemos que alguns conteúdos próprios da tradição gramatical escolar apareceram apenas ou quase que exclusivamente nas três seções dedicadas à "análise linguística": "Ortografia" (282 atividades de um total de 289); "Classes de palavras" (225 de um total de 232), "Emprego de letras maiúsculas" (12 de um total de 16); "Frase, oração e período" (5 de um total de 5) e "Ordem alfabética" (20 de um total de 20).

Por outro lado, encontramos na coleção PA conteúdos de "análise lingüística" que não apareceram nas seções especificamente destinadas a este eixo didático. É o caso de "Efeitos de sentido decorrentes do uso de recursos lingüísticos e/ou gráfico-visuais", "Revisão de texto" e "Uso do dicionário". Observamos, ainda, que outros conteúdos também tendiam a aparecer em seções não-específicas de "análise linguística", como é o caso de "Características de gêneros, tipos ou suportes de texto", "Coesão textual" e "Variação lingüística", os quais se concentraram, de um modo geral, nas seções "Estudo do texto", "Outro texto" e "Produção escrita". Esses conteúdos não estão, diferentemente dos anteriores, ligados à gramática escolar tradicional e, ao contrário daqueles, refletem uma concepção de "análise da língua" que inclui também os aspectos textuais e discursivos.

No caso da coleção PP, observamos que, de um modo geral, todos os conteúdos apareceram na seção "Estudo da língua", com exceção de 
"Revisão de texto", que se concentrou nas seções "Produção de texto" e "Texto". Em outras palavras, apareceram naquela seção tanto conteúdos "clássicos" no ensino da gramática escolar (classes de palavras, ortografia, pontuação, etc.) como outros mais recentemente considerados no âmbito do estudo dos conhecimentos linguísticos (características de gêneros textuais, efeitos de sentido provocados pelo autor do texto, coesão, variação linguística, etc.). Esses resultados parecem confirmar, portanto, o caráter amplo da seção "Estudo da língua", o que é, inclusive, assumido no MP da coleção PP.

Por outro lado, constatamos que alguns conteúdos tendiam a concentrar-se mais naquela seção, enquanto outros apareciam mais distribuídos em outras seções da coleção. No primeiro caso, encontramos, sobretudo, os conteúdos típicos da gramática escolar tradicional (classes de palavras, ortografia, pontuação, emprego de letras maiúsculas, etc.), mas não só, pois observamos também, neste caso, uma concentração de atividades relativas à exploração de efeitos de sentido pretendidos pelos autores dos textos e ao uso do dicionário. No segundo caso, encontramos conteúdos mais distantes da tradição gramatical, como características de gêneros textuais, revisão de textos, coesão e variação linguística, que apareceram em seções como "Vamos estudar o texto", "Produção de texto" e "Texto".

No caso da coleção CLP, vemos que predominaram nas seções clássicas de "análise linguística" ("Descobrindo a gramática" e "Atividades de ortografia") os conteúdos da gramática escolar (classes de palavras e ortografia). É bem verdade que encontramos, também, na seção "Descobrindo a gramática", conteúdos outros que não aqueles, como os vinculados a características de gêneros textuais, efeitos de sentido visados pelo autor do texto e coesão, mas estes tendiam a concentrar-se nas seções "Atividades de linguagem" e "Atividades de textualização".

\section{Que tratamento didático era dado à gramática/análise linguística?}

Para analisar o tratamento didático dado à gramática/análise linguística, consideramos apenas os exercícios relativos aos três conteúdos mais frequentes nas coleções analisadas (ortografia, classes de palavras e 
características de gêneros, tipos ou suportes de texto), examinando o tipo de operação envolvido (identificação, classificação, comparação, produção, etc.) e a unidade sobre a qual o aluno trabalhava (letra/fonema, sílaba, palavra, texto, etc.).

Considerando a relação entre os conteúdos abordados e o tipo de operação explorado nos exercícios, constatamos que enquanto as operações de produção - construção de unidades (meta)linguísticas "próprias" - e de identificação - reconhecimento de unidades (meta)linguísticas que pertenciam a uma mesma classe - eram as mais frequentes no caso da "ortografia" e das "classes de palavras", as de análise - reflexão sobre unidades (meta)linguísticas, envolvendo, na maioria das vezes, a explicitação de características, propriedades, princípios ou regras relativos àquelas unidades - eram, por sua vez, as mais comuns no caso das "características dos gêneros, tipos ou suportes de texto", conforme podemos observar na Tabela 2. Eis alguns exemplos:

Pense em outras palavras que tenham sílabas terminadas em $\boldsymbol{m}$ ou $\boldsymbol{n}$. Escreva 3 palavras que tenham sílabas terminadas com $\boldsymbol{m}$ e $3 \mathrm{com} \boldsymbol{n}$. (CLP2, p. 89)

Existem outros pronomes possessivos no texto "As mil e uma noites"? Procure e escreva no caderno os pronomes possessivos.

(CLP4, p. 131)

Discuta a questão abaixo com seu professor e colegas. Depois, registre a conclusão.

Os cartazes são geralmente bem ilustrados, com textos curtos e escritos com letras grandes.

Na sua opinião, por que isso acontece?

(PA4, p. 176)

No primeiro exemplo, que é uma atividade de produção, os alunos são solicitados a escrever palavras com $\mathrm{M}$ ou $\mathrm{N}$, nasalizando o final de sílabas (manga, melancia, bọmba, lâmpada, etc.). Já no segundo exemplo, que é uma atividade de identificação, solicita-se o reconhecimento de pronomes possessivos em um texto. No último exemplo, que é uma atividade de análise, encontramos uma análise de características do gênero cartaz relativas à estrutura composicional e ao estilo ("bem ilustrados, com textos curtos e escritos com letras grandes"). 
Tabela 2 - Distribuição dos exercícios de "ortografia", "classes de palavras" e "características de gêneros, tipos ou suportes de texto", por atividade, nas coleções de livros didáticos analisadas

\begin{tabular}{|c|c|c|c|c|c|c|c|c|c|}
\hline \multirow{2}{*}{$\begin{array}{l}\text { Conteúdos } \\
\text { Atividades }\end{array}$} & \multicolumn{3}{|c|}{ Ortografia } & \multicolumn{3}{|c|}{ Classes de palavras } & \multicolumn{3}{|c|}{$\begin{array}{l}\text { Caracteristicas dos } \\
\text { gêneros, tipos ou } \\
\text { suportes de texto }\end{array}$} \\
\hline & PA & PP & CLP & PA & PP & CLP & PA & PP & CLP \\
\hline & $\%$ & $\%$ & $\%$ & $\%$ & $\%$ & $\%$ & $\%$ & $\%$ & $\%$ \\
\hline Identificação & 20,7 & 20,2 & 25,4 & 27,0 & 42,1 & 31,3 & 19,7 & 23,1 & 30,9 \\
\hline Classificaçāo & 9,1 & 7,1 & 12,4 & 2,5 & 7,9 & 5,6 & 0,0 & 0,6 & 1,8 \\
\hline Comparação & 8,8 & 9,9 & 13,5 & 3,0 & 1,8 & 5,6 & 6,7 & 7,1 & 5,5 \\
\hline Análise & 22,3 & 8,5 & 5,9 & 24,1 & 10,4 & 5,6 & 57,0 & 38,5 & 30,9 \\
\hline Produçấo & 23,2 & 27,7 & 29,7 & 30,4 & 25,0 & 37,5 & 8,3 & 26,9 & 7,3 \\
\hline Conceituaçăo & 0,0 & 0,0 & 1,1 & 5,5 & 1,8 & 1,4 & 3,6 & 1,9 & 5,5 \\
\hline Denominação & 2,8 & 0,0 & 0,5 & 6,3 & 6,7 & 6,3 & 4,1 & 1,3 & 1,8 \\
\hline Outros & 13,2 & 26,6 & 11,4 & 1,3 & 4,3 & 6,9 & 0,5 & 7,1 & 16,4 \\
\hline Total & 100,0 & 100,0 & 100,0 & 100,0 & 100,0 & 100,0 & 100,0 & 100,0 & 100,0 \\
\hline
\end{tabular}

PA: Porta Aberta

PP: Projeto Pitanguá

CLP: Os caminhos da Língua Portuguesa

Nesse sentido, as atividades de análise foram mais frequentes no caso das "características dos gêneros, tipos ou suportes de texto", o que se expressou, também, no baixo índice que elas apresentaram no caso da "ortografia" e das "classes de palavras", em duas das três coleções analisadas (PP e CLP). Dito de outro modo, em duas das coleções analisadas, parecia haver uma dificuldade em apresentar atividades de análise, quando se tratava dos conteúdos do ensino tradicional da gramática escolar (ortografia e classes de palavras), muito marcados pela repetição/memorização.

Tais dados parecem apontar, assim, para a necessidade de um debate urgente sobre a inovação do tratamento didático de certos conteúdos da tradição do ensino da gramática escolar, que, por terem um papel no desenvolvimento da competência linguística dos alunos, não podem ser simplesmente abandonados ou continuarem sendo tratados como um "mal necessário", mantido à custa de um ensino meramente transmissivo, como acontece, por exemplo, com a ortografia e a concordância verbo-nominal. 
Com relação às atividades de classificação e de comparação, constatamos que elas ocorreram pouco, ou muito pouco, no estudo das "classes de palavras" e no das "características dos gêneros, tipos ou suportes de texto", mas não no da "ortografia". Salientamos, no entanto, que a classificação e comparação de palavras ou de textos constituiria uma estratégia adequada para a exploração de suas características. No caso dos gêneros, isto permitiria ao aprendiz tomar consciência de diferentes propriedades (textuais, sintáticas, estilísticas, etc.) de gêneros semelhantes ou distintos, além de possibilitar o exercício de estratégias de compreensão de leitura que envolvem a intertextualidade.

Por outro lado, observamos, de modo geral, um investimento não expressivo em atividades de "conceituação" e de "denominação", o que parece atestar mais uma tentativa de distanciamento do ensino pouco produtivo de conceitos e nomenclaturas com fins em si mesmos (Geraldi, 1997; Neves, 2003; Antunes, 2007). Se esse pouco investimento pode estar relacionado às críticas ao estudo de conceitos e nomenclaturas com um fim em si mesmo, acreditamos que também pode haver, pelo menos no caso da ortografia, alguma relação com a natureza do próprio conteúdo, que não se adequaria à exploração de conceitos e denominações. Mas isso não significa que as coleções não usavam mais terminologias gramaticais: elas apenas não cobravam explicitamente (ou cobravam pouco) esse conhecimento dos alunos. Vejamos alguns exemplos:

Observe no texto as palavras vampiro, lobisomem, avião, trovão e ladrão.

- A que classe gramatical elas pertencem?

(PP3, p. 100)

Um poema é composto de estrofe e versos.

- Leia uma das estrofes do poema:

"Uma coisa, no entanto,

impede que eu me levante:

sentado nas minhas costas,

há um enorme elefante."

Nessa estrofe há quatro versos.

- Agora, junte-se a um colega e discutam o que vocês acham que é verso e o que é estrofe. Depois registre a conclusão no caderno.

(PA2, p. 202)

Quanto às unidades (meta)linguísticas exploradas nos exercícios dos livros didáticos, constatamos que a/o "letra/fonema", a "palavra" e o "texto" 
eram as unidades privilegiadas, respectivamente, no estudo da "ortografia, das "classes de palavras" e das "características dos gêneros, tipos ou suportes de texto", tal como se pode perceber na Tabela 3. Esses resultados indicam, assim, uma relação entre os conteúdos de ensino e as unidades exploradas, contrariando uma hipotética expectativa de que o "texto" deveria constituir, sempre, a unidade de ensino do Português. Se, na maioria das vezes, isto é verdade, em outras, como no ensino da "ortografia", essa exigência não assume nenhum caráter obrigatório.

Tabela 3 - Distribuição dos exercícios de "ortografia", "classes de palavras" e "características de gêneros, tipos ou suportes de texto" por unidade (meta)linguística, nas coleções de livros didáticos analisadas

\begin{tabular}{|c|c|c|c|c|c|c|c|c|c|}
\hline \multirow{2}{*}{$\begin{array}{l}\text { Conteúdos } \\
\text { Unidades }\end{array}$} & \multicolumn{3}{|c|}{ Ortografia } & \multicolumn{3}{|c|}{ Classes de palavras } & \multicolumn{3}{|c|}{$\begin{array}{l}\text { Caracteristicas dos } \\
\text { gêneros, tipos ou } \\
\text { suportes de texto }\end{array}$} \\
\hline & PA & PP & CLP & PA & Pp & CLP & PA & Pp & CLP \\
\hline & $\%$ & $\%$ & $\%$ & $\%$ & $\%$ & $\%$ & $\%$ & $\%$ & $\%$ \\
\hline Letra/fonema & 47,8 & 57,1 & 62,2 & 1,6 & 0,0 & 0,7 & 0,0 & 1,3 & 0,0 \\
\hline Silaba & 8,4 & 3,9 & 8,1 & 0,0 & 0,0 & 1,4 & 0,0 & 0,6 & 0,0 \\
\hline Morfema & 14,6 & 19,5 & 3,8 & 11,8 & 9,8 & 10,3 & 2,6 & 7,7 & 12,7 \\
\hline Palavra & 19,3 & 14,5 & 20,5 & 61,0 & 68,3 & 65,1 & 2,1 & 1,3 & 1,8 \\
\hline Frase/oração/periodo & 6,2 & 2,8 & 2,7 & 3,3 & 9,8 & 8,9 & 4,7 & 6,4 & 7,3 \\
\hline Parágrafo/trecho de texto & 0,0 & 0,4 & 0,0 & 5,3 & 1,8 & 0,7 & 9,3 & 3,8 & 5,5 \\
\hline Texto & 0,0 & 0,0 & 0,0 & 5,3 & 0,6 & 6,2 & 73,6 & 75,6 & 61,8 \\
\hline Outros & 0,9 & 1,8 & 1,1 & 0,0 & 0,0 & 0,0 & 0,0 & 0,0 & 3,6 \\
\hline Total & 100,0 & 100,0 & 100,0 & 11,4 & 9,8 & 6,8 & 100,0 & 100,0 & 100,0 \\
\hline
\end{tabular}

PA: Porta Aberta

PP: Projeto Pitanguá

CLP: Os caminhos da Língua Portuguesa

Nessa mesma perspectiva, vimos que, enquanto as unidades linguísticas maiores (texto, parágrafos, frases, etc.) ocorriam muito pouco (ou não apareciam) no caso da "ortografia" e no das "classes de palavras", as unidades menores da língua (letra/fonema, sílaba, palavra, etc.) estavam ausentes, ou muito pouco presentes, no caso das "características dos gêneros, tipos ou suportes de texto". 
$\mathrm{Na}$ análise do tratamento dado ao ensino dos três conteúdos mais frequentes nas coleções examinadas ("ortografia", "classes de palavras" e "características dos gêneros, tipos ou suportes de texto"), observamos algumas mudanças, ou tentativas de mudança, que, muitas vezes, apareciam acompanhadas de permanências em relação ao antigo ensino de gramática. Essas continuidades e descontinuidades estavam relacionadas, basicamente, a dois aspectos principais: o "uso de textos" e a "apresentação de informações".

Com relação ao uso de textos no estudo de conteúdos da tradição do ensino da gramática escolar (especialmente ortografia e classes de palavras), constatamos que as coleções analisadas demonstravam uma busca de apropriação de um discurso muito difundido na década de 1980 - "trabalhar com textos" no ensino de conhecimentos gramaticais e ortográficos -, embora nem sempre se encontrasse, é claro, uma coincidência total entre o que tem sido defendido no âmbito dos discursos acadêmicos e oficiais - estudo das funções que determinadas categorias gramaticais assumem nos textos, ou, mais recentemente, nos gêneros - e o que os livros didáticos, às vezes, apresentavam: "uso do texto como pretexto".

Observamos, ainda, que as coleções analisadas usavam não apenas textos de circulação social, os quais não foram produzidos pelos autores da coleção especialmente para o livro didático, como também textos elaborados com esse propósito, que, muitas vezes, adotavam a forma composicional de gêneros de circulação social. No caso da "ortografia" e das "classes de palavras", os autores dos livros didáticos elaboravam "textos" que, intencionalmente, apresentavam os conteúdos que seriam abordados. Já no caso das "características dos gêneros, tipos ou suportes de texto", acreditamos que os autores tendiam a forjar "textos" que tinham claramente as características do gênero que se pretendia explorar, evitando, assim, textos mais maleáveis quanto às características do gênero.

Com relação à apresentação de informações sobre os conteúdos gramaticais ou linguísticos estudados, constatamos que, no caso da ortografia e no das classes de palavras - conteúdos "clássicos" do ensino da gramática escolar -, havia um interesse em não apresentar regras, conceitos ou nomenclaturas "prontos", pelo menos de início. Por outro lado, no caso das "características dos gêneros, tipos ou suportes de texto" - conteúdo 
considerado "novo" no ensino de "conhecimentos linguísticos" -, notamos que as coleções transmitiam - não só depois das atividades, mas também antes - uma série de informações sobre os gêneros explorados (conceito, denominação, características formais específicas, etc.).

Nos livros didáticos analisados, observamos que essa combinação entre "antigo" e "novo" apareceu claramente, por exemplo, no estudo das "classes de palavras": as coleções mantiveram o ensino das categorias gramaticais tradicionais, apresentando as classes uma a uma (substantivo, adjetivo, artigo, pronome, etc.), tal como acontecia no "antigo" ensino da gramática escolar, mas, ao mesmo tempo, traziam algumas "inovações" em relação a esse ensino, como relativização da gramática (relativização do conceito ou da classificação das palavras, seja em relação à forma, seja em relação à posição delas na frase, oração), exploração de aspectos textuais, consideração da norma de uso real da língua e tendência à não-apresentação de conceitos e nomenclaturas no início do estudo das classes.

\section{Para concluir}

Como indicaram os resultados deste estudo, os "novos" livros didáticos brasileiros de Língua Portuguesa estão apresentando, sim, tentativas de mudança em relação ao antigo ensino de gramática escolar, embora não exatamente da mesma maneira como tem sido defendido nos discursos acadêmicos e oficiais sobre "análise linguística". Essa constatação contrariaria, portanto, as expectativas de muitos daqueles que estabelecem o que e como deve ser o ensino de língua na escola.

No entanto, as inovações observadas nos livros didáticos brasileiros não substituíram, inteiramente, as "velhas" maneiras de ensinar gramática, mas revelaram tentativas de mudança em tempos de transição. Por isso, as coleções analisadas apresentavam, por exemplo, não apenas "mudanças na estabilidade" (mantinha-se o ensino de classes de palavras, mas as classificações eram relativizadas), como também "estabilidades na mudança" (transmitiam-se informações sobre as características dos gêneros textuais). Segundo Mendonça (2006a), "atravessamos um momento especial, em que convivem 'velhas' e 'novas' práticas no espaço da aula de gramática, por vezes, conflituosas" (p. 201). 
Se os livros didáticos por nós examinados exploravam as "classes de palavras", considerando, por exemplo, o papel textual das categorias gramaticais, nem por isso eles abriam mão de determinados procedimentos "antigos", como retirar palavras do texto, mesmo que, para isso, as duas coisas aparecessem associadas, no mesmo exercício. Esses resultados parecem, assim, se relacionar à "coerência pragmática" (Chartier, 2000) adotada pelos professores, ao tentar inovar o ensino não só da gramática, mas também da leitura e produção de textos, conforme demonstrado em distintos estudos (Morais, 2002; Albuquerque, 2002; Santos, 2004; Aparício, 2006).

Em suma, o que aparece nos livros didáticos brasileiros, por nós analisados, não é o resultado de uma mera transposição didática (Chevallard, 1991) direta dos discursos acadêmicos e oficiais sobre o ensino de "gramática" ou "análise linguística" na escola, nem uma construção inteiramente original (Chervel, 1988), mas uma espécie de "acomodação" dos discursos inovadores aos antigos modos de ensinar gramática.

Compreendendo que este estudo poderá oferecer subsídios à avaliação e à produção de livros didáticos, esperamos que contribua, mais amplamente, para a discussão sobre as atuais mudanças no ensino de Língua Portuguesa, tendo a consciência de que, um dia, elas não serão mais tão "novas", mas, mesmo assim, merecerão, talvez, ser ainda (re)interpretadas.

\section{Notas}

1 Este trabalho contou com o apoio do Conselho Nacional de Desenvolvimento Científico e Tecnológico - CNPq/Brasil.

2 Atualmente, a educação escolar brasileira compõe-se de Educação Básica, constituída pela Educação Infantil (destinada a crianças de até 5 anos de idade), Ensino Fundamental (com duração de 9 anos, iniciando-se aos 6 anos de idade, embora ainda existam redes de ensino em que as crianças ingressam aos 7 anos e cursam o Ensino Fundamental em 8 anos) e Ensino Médio (com duração mínima de três anos), e Educação Superior.

3 Neste estudo, o termo 'tradicional' não assume, necessariamente, um sentido negativo, relacionando-se, muito mais, a um conjunto de práticas que se solidificaram com o passar do tempo, com regularidade de ocorrência, o que terminou por constituir uma 'tradição' (Mendonça, 2006a, p. 201). 
4 Os livros didáticos recebiam, até 2004, as seguintes menções: recomendado com distinção; recomendado; recomendado com ressalvas; não recomendado; excluído.

5 Como o site do FNDE não informa os dados por Estado, fizemos um levantamento por município (disponível em: www.fnde.gov.br. Acesso em: 15/08/2007).

6 Para essa análise, consideramos apenas a seção gramática ou a sua substituta, não incluindo, por exemplo, as seções relativas à ortografia.

7 Estão incluídas nesta categoria as atividades que exploravam as características de diversos gêneros textuais, sejam elas relativas ao conteúdo, à estrutura do texto e aos recursos lingüísticos e extralinguísticos utilizados, sejam relativas à finalidade, aos interlocutores e ao espaço de circulação dos textos. Consideramos, também neste caso, as atividades voltadas à exploração de tipos textuais (como narrativo, descritivo, expositivo e argumentativo) e de suportes de texto (livro, revista, jornal, etc.).

\section{Referências}

Albuquerque, E. B. C. (2002). Apropriações de Propostas Oficiais de Ensino de Leitura por Professores: o Caso de Recife. Tese de doutorado não publicada. Belo Horizonte: Universidade Federal de Minas Gerais.

Antunes, I. (2007). Muito Além da Gramática: por um Ensino de Línguas sem Pedras no Caminho. São Paulo: Parábola.

Aparício, A. S. M. (2006). A Produção da Inovação em Aulas de Gramática do Ensino Fundamental Il da Escola Pública Estadual Paulista. Tese de doutorado não publicada. Campinas: Universidade Estadual de Campinas.

Bardin, L. (1979). Análise de conteúdo. Lisboa: Edições 70.

Batista, A. A. G., \& Costa Val, M. G. (2004). Livros didáticos, controle do currículo, professores: uma introdução. In A. A. G. Batista \& M. G. Costa Val (Orgs.), Livros Didáticos de Alfabetização e de Português: os Professores e suas Escolhas. Belo Horizonte: Autêntica.

Batista, A. A. G. (1997). Aula de Português: Discursos e saberes Escolares. São Paulo: Martins Fontes.

Biruel, A. M. S. (2002). Análise Linguística nos Livros Didáticos Recomendados pelo PNLD 2000-2001: o tratamento dado aos aspectos de normatividade. Dissertação de mestrado não publicada. Recife: Universidade Federal de Pernambuco.

Brasil (2006). Guia de livros didáticos: $1^{a}$ a $4^{a}$ séries - PNLD 2007. Brasília: Ministério da Educação.

Chartier, A.-M. (2000). Réussite, échec et ambivalence de l'innovation pédagogique: le cas de l'enseignement de la lecture. Recherche et Formation, innovations et réseaux sociaux, 34, 41-56.

Chervel, A. (1988). L'histoire des disciplines scolaires: réflexions sur un domaine de recherche. Histoire de l'éducation, 38, 59-119. 
Chevallard, Y. (1991). La Transposición Didáctica: del Saber Sabio al Saber Enseñado. Buenos Aires: Aique.

Costa Val, M. da G., \& Castanheira, M. L. (2005). Cidadania e ensino em livros didáticos de alfabetização e de língua portuguesa (de $1^{a}$ a $4^{a}$ série). In M. G. Costa Val \& E. Marcuschi (Orgs.), Livros Didáticos de Língua Portuguesa: Letramento e Cidadania. Belo Horizonte: Autêntica.

Geraldi, João W. (1997). Concepções de linguagem e ensino de Português. In J. W. Geraldi (Org.), O Texto na Sala de Aula: Leitura e Produção. Cascavel: Assoeste.

Laville, C., \& Dionne, J. (1999). A Construção do Saber: Manual de Metodologia da Pesquisa em Ciências Humanas. Porto Alegre: Artmed; Belo Horizonte: Editora UFMG.

Marinho, M. (1998). A Língua Portuguesa nos currículos de final de século. In E. de S. Barreto et al., Os Currículos do Ensino Fundamental para as Escolas Brasileiras. Campinas: Autores Associados; São Paulo: Fundação Carlos Chagas.

Mendonça, M. R. S. (2006a). Análise lingüística no ensino médio: um novo olhar, um outro objeto. In M. Bunzen \& C. Mendonça (Orgs.), Português no Ensino Médio e Formação do Professor. São Paulo: Parábola.

Mendonça, M. R. S. (2006b). Análise linguística: refletindo sobre o que há de especial nos gêneros. In C. F. Santos, M. Mendonça \& M. C. B. Cavalcante (Orgs.), Diversidade Textual: os Gêneros na Sala de Aula. Belo Horizonte: Autêntica.

Morais, A. G. (2002). Mostro à solta ou... Análise Linguística na escola: apropriações de professoras das séries iniciais ante as novas prescrições para o ensino de Gramática. Comunicação apresentada na 25a Reunião Anual da ANPEd, Caxambu.

Neves, M. H. M. (2003). Que Gramática Estudar na Escola? São Paulo: Contexto.

Neves, M. H. M. (1990). Gramática na Escola. São Paulo: Contexto.

Santos, C. F. (2004). O Professor e a Escrita: entre Práticas e Representações. Tese de doutorado não publicada. Campinas: Universidade Estadual de Campinas.

Schneuwly, B., \& Dolz, J. (2004). Gêneros Orais e Escritos na Escola. Campinas: Mercado de Letras.

Silva, N. N. T., \& Silva, A. (2010). Concepções e práticas de ensino de gramática ou análise linguística de professores dos anos iniciais do ensino fundamental. In XVIII CONIC, 2010, Recife. Anais do XVIII CONIC.

Soares, M. (1998). Concepções de linguagem e o ensino da Língua Portuguesa. In N. B. Bastos (Org.), Língua Portuguesa: História, Perspectivas, Ensino. São Paulo: EDUC.

Souza, S. B. (2010). Entre o Ensino da Gramática e as Práticas de Análise Linguística: o que pensam e fazem os Professores do Ensino Fundamental? Dissertação de mestrado não publicada. Recife: Universidade Federal de Pernambuco. 


\title{
BETWEEN TRADITION AND INNOVATION: A STUDY REGARDING THE CHANGES IN THE TEACHING OF GRAMMAR FOUND IN THE PORTUGUESE LANGUAGE TEXTBOOK
}

\begin{abstract}
The purpose of this article is to investigate the treatment given to grammar teaching or to the linguistic analysis in three Brazilian collections of Portuguese textbooks approved by the 2007 National Textbook Program. The results point out that two of the analyzed collections used the term grammar and all of them tended to establish educational objectives related to the mastery of the grammar or the language themselves. Regarding the contents, we verified that the traditional topics of school grammar shared the stage with other contents. As we analyzed the activities, we found, in two of the collections, few analytical activities when it came to the traditional contents. At the teaching of the word classes and spelling, we found two main innovations: the use of texts and the tendency to the non-presentation of ready information. At the exploration of the characteristics of textual genders, in addition to using pseudo-texts, the collections adopted, sometimes, a transmissive approach.
\end{abstract}

Keywords

Linguistics analysis; Grammar teaching; Portuguese textbooks ENTRE TRADITION ET INNOVATION: UNE ÉTUDE SUR DES CHANGEMENTS
DANS L'ENSEIGNEMENT DE LA GRAMMAIRE DANS DES MANUELS
DIDACTIQUES BRÉSILIENS DE LANGUE PORTUGAISE

\section{Résumé}

L'objectif de cet article est enquêter le traitement donnée à l'«enseignement de la grammaire» ou à l'«analyse linguistique» dans trois collections brésiliennes de manuels didactiques de Langue Portugaise approuvés dans le Programme National du Manuel Didactique 2007. Les résultats ont montré que deux des collections analysées utilisaient le terme «grammaire» et toutes tendaient à 
établir des objectifs d'enseignement rapportés au domaine de la grammaire ou de la langue même. Concernant les contenus, nous avons constaté que les sujets traditionnels de la grammaire scolaire divisaient la scène avec d'autres contenus. En analysant les activités, nous avons observé, en deux collections, peu d'activités d'«analyse» quand ils s'agissait des contenus «traditionnels». Dans l'enseignement des «classes de mots» et de l'«orthographe», nous avons trouvé deux innovations principales: l'emploi de textes et la tendance à la non-présentation d'informations «prêtes». En revanche, dans l'exploration des «caractéristiques des genres textuels», au-delà d'utiliser des pseudotextes, les collections adoptaient, quelquefois, une approche transmissive.

Mots-clé

Analyse linguistique; Enseignement de la grammaire; Manuels didactiques

Recebido em Dezembro/2009 Aceite para publicação em Agosto/2010 